\title{
Letter to Editor: You Might Transmit COVID-19 Only Via Talking; A Speech Therapy Perspective
}

\author{
Majid Ravanbakhsh $^{1}$ (D), Peyman Zamani ${ }^{* *}$ (D) \\ 1. Musculoskeletal Rehabilitation Research Center, Ahvaz Jundishapur University of Medical Sciences, Ahvaz, Iran. \\ 2. Department of Speech Therapy, School of Rehabilitation Sciences, Ahvaz Jundishapur University of Medical Sciences, Ahvaz, Iran.
}

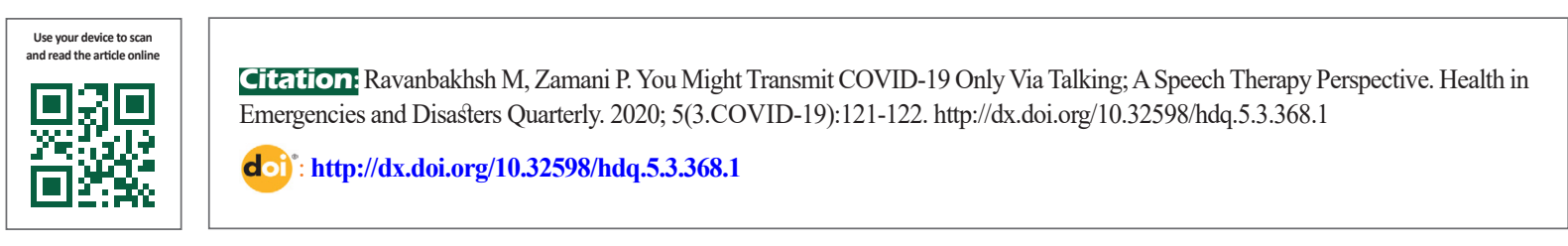

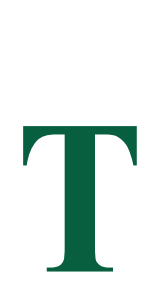

\section{Dear Editor}

he Coronavirus disease 2019 (COVID-19)

was identified in late 2019 and has gradually spread to all countries. Following the outspread of this virus as a communityacquired disease, many researchers have been trying to identify various factors involved in the transmission of the virus, as well as the ways to prevent its transmission from person to person. For example, researchers have found that ambient temperatures above $40^{\circ} \mathrm{C}$ and proper ventilation prevent the growth, proliferation, and transmission of the severe acute respiratory syndrome coronavirus 2 (SARS$\mathrm{CoV}-2$ ), however; environmental humidity is largely ineffective for its transmission $[1,2]$.

Martelletti and Martelletti (2020) stated that air pollution could exacerbate the prevalence of COVID-19 [3]. One of the main ways of transmitting the COVID-19 is through the hurl and release of droplets and secretions containing the virus during sneezing or coughing or even during breathing through the upper respiratory tract and mouth of infected people or carriers without clinical signs [4]. Therefore, it seems that some speech-related factors may also increase the risk of transmitting the virus during a conversation between the infected speaker or the carrier in a non-mask and face protection mode [5]. These factors can be divided into three categories:
Psycholinguistic factors of speakers

Persons who habitually speak quicker, louder with more energy compared with normal mode are characterized by exaggerated articulation. Therefore, they might spray particles and droplets meters away from their mouth due to the exaggerated usage of the speech articulators when producing high-pressure plosive sounds, such as $/ p, t, k /[6]$.

\section{Anatomical-based speech disorders}

The risk of hurling droplets containing the SARSCoV-2 from the mouth of people with oro-facial abnormalities, such as the lack of anterior teeth (the incisors), the jaw with a class III malocclusion, unrepaired cleft lip and palate, or ones who have oral assistive devices, such as dentures and dental orthodontics is more than others due to incomplete closure of the lips or other articulators at the time of speaking [7].

\section{Functional-based speech disorders}

People with lisp speech disorders due to the opening of the space between the lips and extra air chamber at the time of production of the fricatives $/ \mathrm{s}, \mathrm{z} /$ and the affricatives $/ t$, dž/ sounds, and also those with severe stutter accompanied by secondary lips movements due to a sudden release of the articulators following the tonic spasms resulting from the stuttering are more likely to drop oral droplets containing the virus [8].

\section{* Corresponding Author:}

Peyman Zamani, PhD.

Address: Department of Speech Therapy, School of Rehabilitation Sciences, Ahvaz Jundishapur University of Medical Sciences, Ahvaz, Iran.

E-mail:zamanipdrsł@gmail.com 
Accordingly, speech therapists are advised to wear face shields, masks, mouth guards, and gloves after reopening speech therapy clinics. They should wash their hands before and after clinical sessions and observe a distance of at least two meters with the clients. Additionally, conservative advice should also be given to clients about COVID-19 transmission. On the other hand, it seems necessary that speech therapists should be present in the interdisciplinary counseling and health teams to determine the risk factors and the possibility of COVID-19 transmission when speaking. Therefore, speech therapy has an important role to identify and reduce the interpersonal transmission of the COVID-19.

\section{Ethical Considerations}

\section{Compliance with ethical guidelines}

All ethical principles are considered in this article.

\section{Funding}

This research did not receive any grant from funding agencies in the public, commercial, or non-profit sectors.

\section{Authors' contributions}

All authors contributed in preparing this article.

\section{Conflict of interest}

The authors declared no conflict of interest.

\section{Acknowledgments}

The authors would like to thank Mrs. Seyedeh Maryam Mousavi for her guidances in writing this article.

\section{References}

[1] Chiyomaru K, Takemoto K. Global COVID-19 transmission rate is influenced by precipitation seasonality and the speed of climate temperature warming [Internet]. [April 2020]. 2020. [DOI:10.1101/2020.04.10.20060459.]

[2] Sun Z, Thilakavathy K, Suresh Kumar S, He G, Liu SV. Potential factors influencing repeated SARS outbreaks in China. International Journal of Environmental Research and Public Health. 2020; 17(5):1633. [DOI:10.3390/ijerph17051633] [PMID] [PMCID]

[3] Martelletti L, Martelletti P. Air pollution and the novel Covid-19 disease: A putative disease risk factor. SN Comprehensive
Clinical Medicine. 2020; 1-5. [DOI:10.1007/s42399-020-00274-4] [PMID] [PMCID]

[4] Huang C, Wang Y, Li X, Ren L, Zhao J, Hu Y, et al. Clinical features of patients infected with 2019 novel coronavirus in Wuhan, China. Lancet. 2020; 395(10223):497-506. [DOI:10.1016/S0140-6736(20)30183-5] [PMID] [PMCID]

[5] Xie X, Li Y, Sun H, Liu L. Exhaled droplets due to talking and coughing. Journal of the Royal Society, Interface. 2009; 6(Suppl 6):S703-14. [DOI:10.1098/rsif.2009.0388.focus] [PMID] [PMCID]

[6] AsadiS, Wexler AS, Cappa CD, Barreda S, Bouvier NM, Ristenpart WD. Aerosol emission and superemission during human speech increase with voice loudness. Scientific Reports. 2019; 9(1):2348. [DOI:10.1038/s41598-019-38808-z] [PMID] [PMCID]

[7] Gupta JK, Lin CH, Chen QY. Characterizing exhaled airflow from breathing and talking. Indoor Air. 2010; 20(1):31-9. [DOI:10.1111/j.1600-0668.2009.00623.x] [PMID]

[8] Inouye S. SARS transmission: Language and droplet production. Lancet. 2003; 12(362):170-70. [DOI:10.1016/S01406736(03)13874-3] [PMID] [PMCID] 